Article

\title{
Dynamic Tension Deformation of Rare-Earth Containing Mg-1.9Mn-0.3Ce Alloy Sheet along the Rolling Direction at Various Temperatures
}

\author{
Jin Wang, Yang Wang * and Ziran Li \\ CAS Key Laboratory of Mechanical Behavior and Design of Materials, Department of Modern Mechanics, \\ University of Science and Technology of China, Hefei 230027, China; wj1995@mail.ustc.edu.cn (J.W.); \\ lzr@ustc.edu.cn (Z.L.) \\ * Correspondence: yangwang@ustc.edu.cn; Tel. +86-551-63601236
}

Received: 30 September 2020; Accepted: 1 November 2020; Published: 4 November 2020

\begin{abstract}
The tensile properties of rare-earth containing $\mathrm{Mg}-1.9 \mathrm{Mn}-0.3 \mathrm{Ce}$ alloy sheet along the rolling direction were experimentally investigated within the strain rate and temperature ranges of $0.001-1300 \mathrm{~s}^{-1}$ and $213-488 \mathrm{~K}$. The obtained stress-strain responses of the alloy sheet indicate that both yield strength and strain-hardening rate increase when the strain rate increases, whereas they decrease with increase of temperature. Microscopic examination results show that basal slip, prismatic slip, and $\{10 \overline{1} 2\}$ tension twinning take place in the tensile plastic deformation, while the occurrence of twinning is not obviously affected by the rate and temperature. Tensile samples tend to fracture in a ductile mode with increasing strain rate and temperature.
\end{abstract}

Keywords: magnesium alloy; tensile behavior; rate-temperature dependence; deformation mechanism; fracture mode

\section{Introduction}

Due to excellent balance between light weight and high strength, magnesium and its alloys have been widely utilized instead of traditional metals [1-5]. Compared to the conventional $\mathrm{Mg}-\mathrm{Al}$ and $\mathrm{Mg}$-Zn alloys, magnesium alloys which contains the rare-earth elements such as yttrium, lanthanum, and cerium have a great ability to have weaker mechanical anisotropy as well as improved corrosion resistance and welding adaptability [6-12]. Rare-earth containing Mg-1.9Mn-0.3Ce alloy is commonly used as a structural component in aerospace and warship industries, where these components maybe subjected to high-speed loadings under extreme ambient temperatures in manufacture and service $[8,13]$. Accordingly, it is necessary to understand the stress-strain responses of this alloy at high loading rates and various temperatures under both tension and compression loadings due to the fact that tension-compression asymmetry of mechanical behavior commonly exists in magnesium alloys. However, owing to the technical complexity for high-rate tensile testing, most experimental investigations concerning high-rate plastic deformation of rare-earth containing magnesium alloys focus on compressive loadings.

As for the tensile stress, strain responses of conventional magnesium alloys such as AZ31 and ZK60, as well as rare-earth-containing magnesium alloys like ZEK100, experimental investigations indicate that tensile properties of magnesium alloys exhibit positive loading-rate sensitivity and negative temperature sensitivity. Moreover, the tensile plastic deformation mechanism in magnesium alloys is found to be related to the loading rate and temperature, and it is generally known that the basal and non-basal slips dominate the tensile plastic deformation of magnesium alloys. For instance, Geng et al. [14] carried out tensile tests on the magnesium alloy AZ31B at the rates of $2.8 \times 10^{-5}$ to $1.1 \times 10^{-1} \mathrm{~s}^{-1}$ at room 
temperature, and the results indicated that basal slip is dominant in tensile plastic deformation, and the contribution of the slips to plastic deformation decreases with the increase of rate. Kurukuri et al. [15] performed in-plane tensile tests on ZEK100 alloy sheet over a wide range of strain rates up to $1000 \mathrm{~s}^{-1}$, and found the yield strength in the rolling direction was strongly rate sensitive and controlled by non-basal slip. Owing to a limited number of active slip systems in the low symmetrical hexagonal-close-packed (HCP) structure, magnesium alloys exhibit poor room-temperature formability, and non-basal slips are more likely to be activated at high temperatures. Wang et al. [16] found that the activity of non-basal slips in the tensile deformation of ZK60 alloy increases with increase of temperature. Habib et al. [17] investigated tensile responses of ZEK100 alloy sheet along the rolling plane at temperatures of 22 and $150{ }^{\circ} \mathrm{C}$, and various strain rates up to $3 \times 10^{3} \mathrm{~s}^{-1}$, and found basal slip and pyramidal $<c+a>$ slip participate in plastic deformation. Twinning is also a significant deformation mechanism for magnesium alloys, which generally arises in the in-plane compression deformations for magnesium alloy sheet, while it seldom occurs under in-plane tensile loadings [18,19]. Wang et al. [20] performed dynamic tensile tests on the extruded AZ31 alloy along the extrusion and transverse directions at a strain rate of $1800 \mathrm{~s}^{-1}$, and observed that $\{10 \overline{1} 2\}$ extension twinning occurs in plastic deformation.

The goal of the present study is to investigate the influences of the loading rate and test temperature on the tensile plastic deformation of a rare-earth containing Mg-1.9Mn-0.3Ce alloy sheet. Uniaxial tensile tests for Mg-1.9Mn-0.3Ce alloy sheet along the rolling direction at temperatures of 213-488 K and at strain rates up to $1300 \mathrm{~s}^{-1}$ were performed. The deformed samples under various loading conditions were examined by means of electron backscatter diffraction (EBSD) and scanning electron microscope (SEM) techniques, and the plastic deformation mechanism and fracture mode analyzed.

\section{Materials and Methods}

A commercial Mg-1.9Mn-0.3Ce alloy was investigated in the form of rolling sheet. The nominal chemical composition (in wt\%) of the alloy was $1.9 \mathrm{Mn}, 0.3 \mathrm{Ce}, 0.002 \mathrm{Zn}, 0.016 \mathrm{Si}, 0.005 \mathrm{Fe}, 0.0001 \mathrm{Be}$, and the balance of $\mathrm{Mg}$. EBSD measurement of the as-received alloy along the rolling/transverse direction was performed, and the initial microstructure is shown in Figure 1. The average size of grains is approximately $10 \mu \mathrm{m}$, and the relatively weak basal texture is formed with a lower maximum intensity compared to typical AZ31 rolled sheet with a maximum intensity of 14.6 [21].
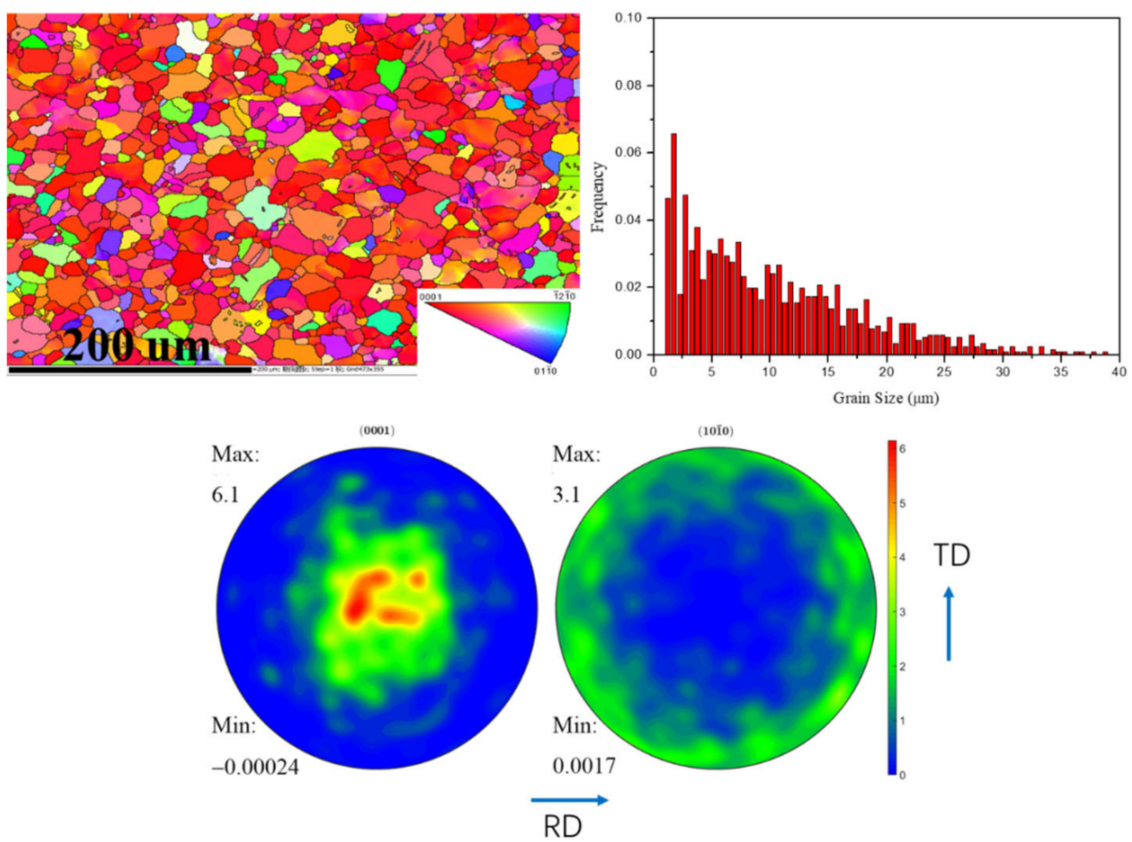

Figure 1. Initial microstructure of as-received Mg-1.9Mn-0.3Ce alloy sheet measured by EBSD. 
The simple tensile tests for the alloy sheet along the rolling direction were conducted under various temperature and strain-rate conditions. Tensile tests at the rates of $1 \times 10^{-3}, 1 \times 10^{-2}$ and $5 \times 10^{-2} \mathrm{~s}^{-1}$ were carried out on the MTS 810 testing machine (MTS systems corporation, Eden Prairie, $\mathrm{MN}$, USA). Dynamic tests at the rates of $3 \times 10^{2}$ and $1.3 \times 10^{3} \mathrm{~s}^{-1}$ were conducted using the split Hopkinson tension bar (SHTB) technique (USTC, Hefei, China), as schematically shown in Figure 2. The measuring principle for the SHTB test is similar to that in the common split Hopkinson pressure bar (SHPB) test, which has been widely used to obtain the dynamic compressive stress-strain responses of metallic materials [22-24]. The main differences between SHTB and SHPB systems are the generation of incident stress pulse and the connection of the sample with incident/transmitted bars as well as sample geometry. Here, the dog-bone-plate-shaped sample was adhesively bonded between the bars. The ambient temperatures of 213-253 K were obtained by adding liquid nitrogen into the cryogenic temperature device (USTC, Hefei, China), and ambient temperatures of 358-488 K were achieved by radiation heating technology (USTC, Hefei, China). The strain histories in the incident/transmitted bars were monitored by strain gages (Hanzhongjingce, Hanzhong, China) bonded on the surfaces of the bars. Based on the one-dimensional measuring principle of elastic stress-wave propagation in the bars, the engineering stress-strain responses of the sample can be obtained [22]. The detailed introduction of the SHTB testing system can be found elsewhere [25].

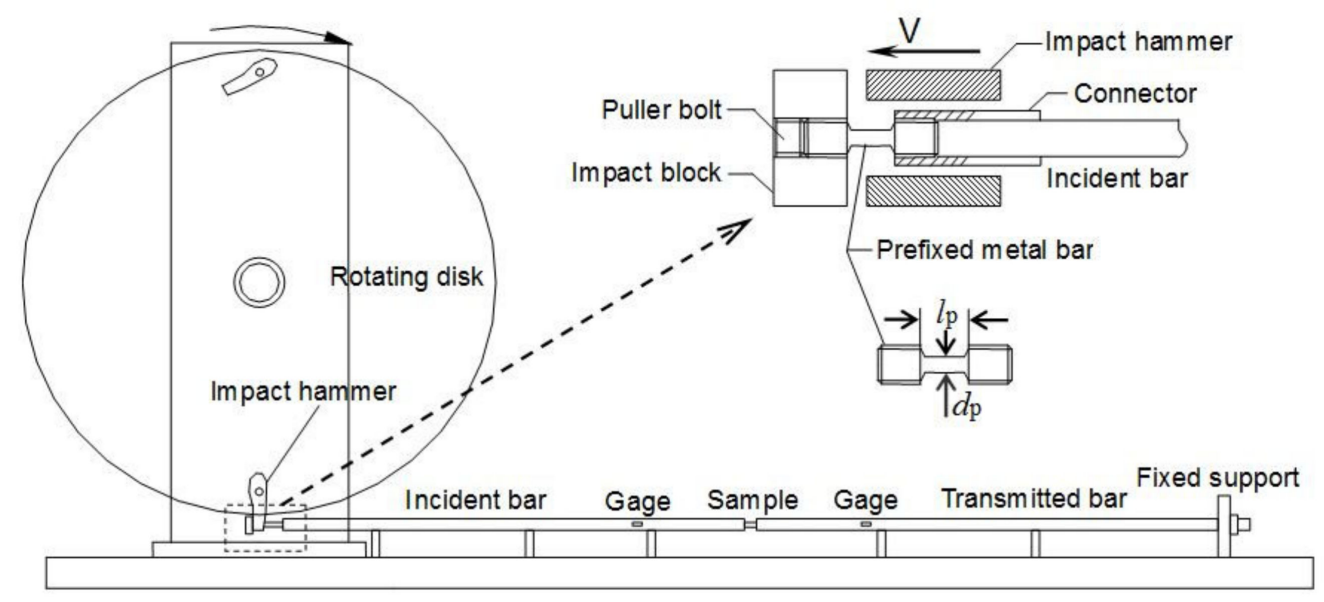

Figure 2. Schematic diagram of the split-Hopkinson tension bar system.

Sample geometries for quasi-static and dynamic tests are shown in Figure 3. To ensure stress equilibrium in the sample and constant strain-rate loading in the SHTB test, the sample used in the high-rate tests had a gage length of $10 \mathrm{~mm}$, gage width of $4 \mathrm{~mm}$, and thickness of $1.1 \mathrm{~mm}$. The sample geometry utilized for quasi-static tests was similar to the dynamic one. However, gage length, $78.6 \mathrm{~mm}$, width $8 \mathrm{~mm}$, and thickness $1.2 \mathrm{~mm}$ were adopted to avoid the end effect which meets the requirement of the GB/T 228.1-2010 tensile testing standard for metallic materials [26]. 


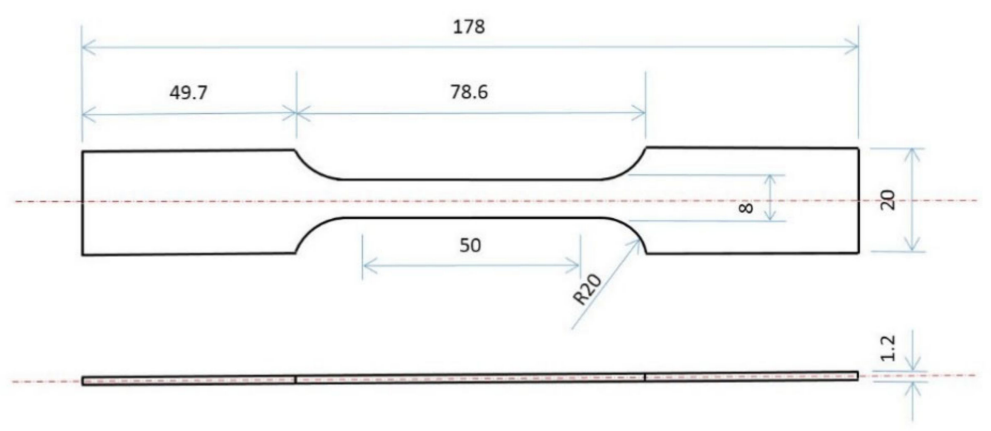

(a)

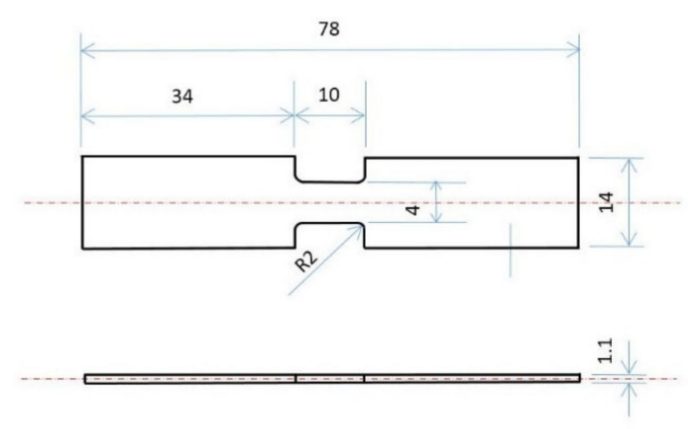

(b)

Figure 3. Tension samples used for (a) quasi-static and (b) dynamic tests. (Units: $\mathrm{mm}$ ).

All samples were machined along the rolling direction of the alloy sheet, and the sample surface was parallel to the rolling plane. To obtain reliable test results, at least three tests were carried out for each loading case. EBSD (Hitachi Limited, Tokyo, Japan) measurements were performed for samples stretched at various strain rates and temperatures. First, the post-deformed samples were mechanically polished, and then ion etching was carried out for precision polishing. An area of $470 \mu \mathrm{m}$ by $310 \mu \mathrm{m}$ was scanned with $1 \mu \mathrm{m}$ step size for each deformed sample.

\section{Results and Discussion}

\subsection{Tensile Behavior at Various Strain Rates and Temperatures}

Figure 4 illustrates the tensile true stress-true strain responses of $\mathrm{Mg}-1.9 \mathrm{Mn}-0.3 \mathrm{Ce}$ alloy sheet as a function of temperature at five strain rates. It is clear that the tensile deformation of $\mathrm{Mg}-1.9 \mathrm{Mn}-0.3 \mathrm{Ce}$ alloy sheet is relatively sensitive to strain rate and test temperature. Both initial yielding and subsequent strain hardening exhibit positive strain-rate dependence and negative temperature dependence. The temperature effect on the tensile deformation for quasi-static and dynamic loadings are different, and such temperature dependence is more pronounced under quasi-static loadings. For example, as for yield strength which corresponds to the true stress at the plastic strain of $0.2 \%$, its value is reduced by $45 \%$ at the rate of $0.001 \mathrm{~s}^{-1}$ and $25 \%$ at the rate of $1300 \mathrm{~s}^{-1}$ within the temperature range of $213-488 \mathrm{~K}$. On the other hand, the effect of strain rate on both initial yielding and strain hardening behavior is more apparent at high temperatures. For instance, a $20 \%$ increase in yield strength is found at $213 \mathrm{~K}$ and strain rates ranging from 0.001 to $1300 \mathrm{~s}^{-1}$, while yield strength increases by $75 \%$ at $488 \mathrm{~K}$, as seen in Figure 5. 

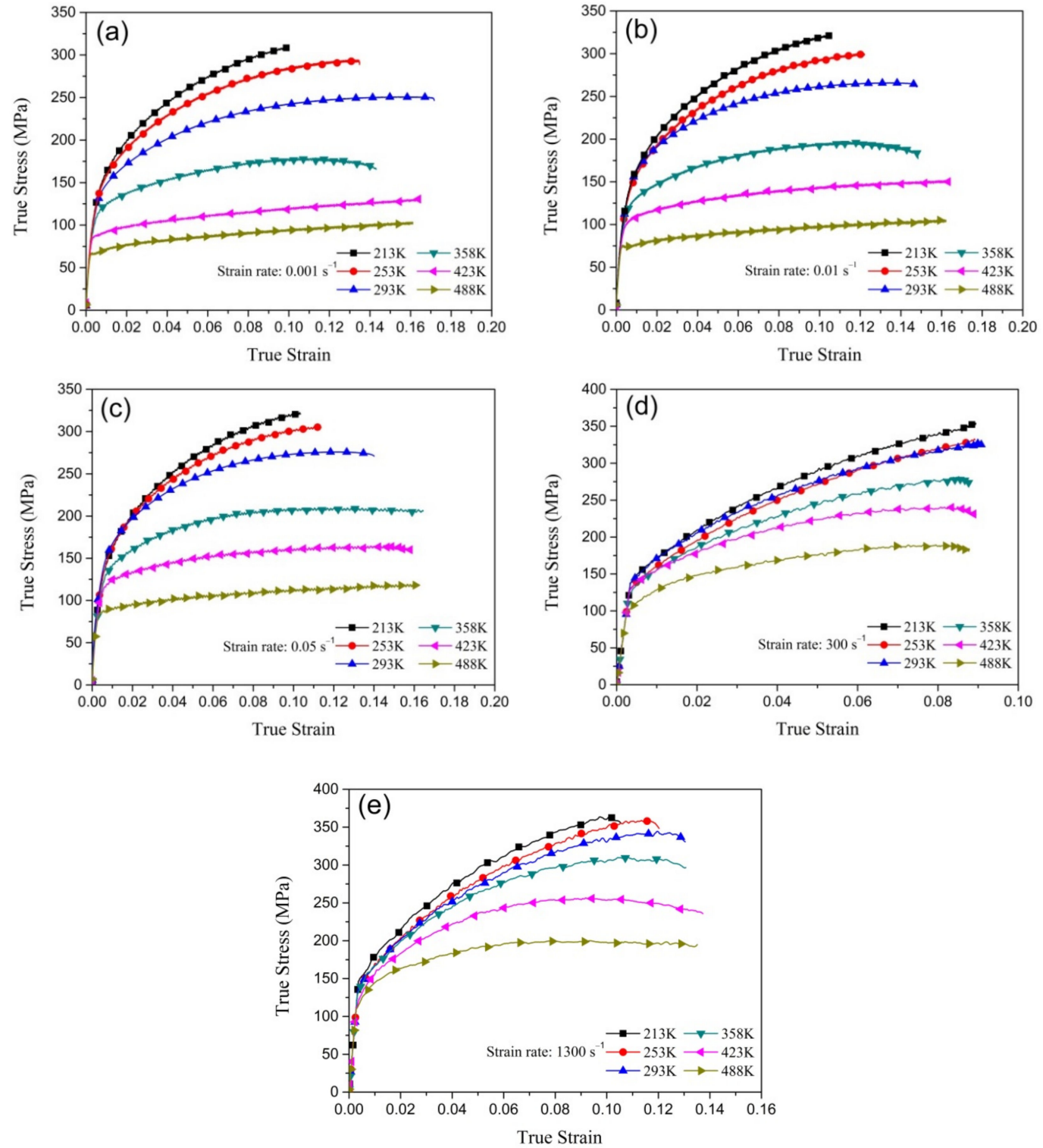

Figure 4. True stress-true strain responses at various temperatures and strain rates of (a) $0.001 \mathrm{~s}^{-1}$, (b) $0.01 \mathrm{~s}^{-1}$, (c) $0.05 \mathrm{~s}^{-1}$, (d) $300 \mathrm{~s}^{-1}$, and (e) $1300 \mathrm{~s}^{-1}$.
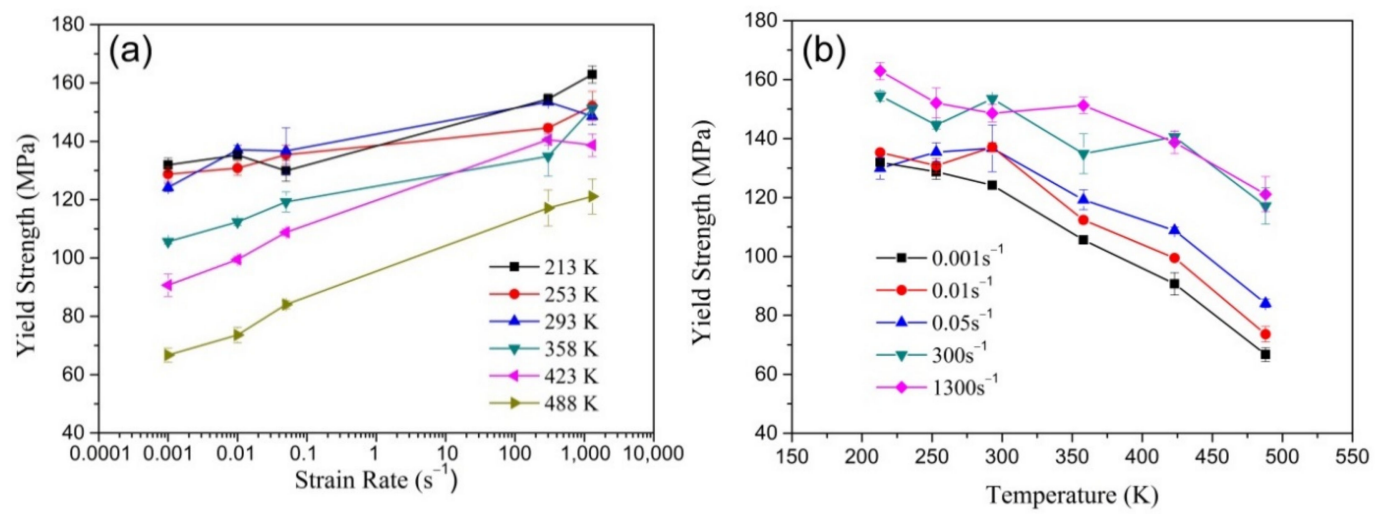

Figure 5. Effects of (a) strain rate and (b) temperature on the values of yield strength.

Figure 5 shows the variation of yield strength with strain rate and temperature. As seen in Figure $5 \mathrm{a}$, the value of yield strength increases almost linearly with logarithm strain rate, and such an 
increasing trend is more obvious at high temperatures. It is noted in Figure $5 b$ that the yield strength decreases with temperature, which is more apparent for quasi-static loadings.

To quantitatively compare the strain-hardening behavior of the alloy sheet at various strain rates and temperatures and evaluate its rate and temperature dependence, the average value for strain hardening rate (SHR) over a given strain range is calculated as

$$
\mathrm{SHR}=\frac{\sigma_{0.06}-\sigma_{0.04}}{0.02}
$$

where $\sigma_{0.06}$ and $\sigma_{0.04}$ are flow stresses at the plastic strains of 0.06 and 0.04 . Namely, the value of SHR corresponds to the slope between the plastic strains of 0.04 and 0.06 , which are extracted from the true stress-true strain responses in Figure 4. The calculated values of SHR at various rates and temperatures are shown in Figure 6. The value of SHR increases when the strain rate is increased, and decreases with increasing temperature. In particular, SHR-temperature curves almost coincide with each other at high strain rates. A similar phenomenon also can be seen under quasi-static loading conditions. Moreover, the values of SHR at the high strain rates of 300 and $1300 \mathrm{~s}^{-1}$ are greater than the quasi-static one for all test temperatures, which is consistent with the experimental results for magnesium alloy ZEK100 [17]. Compared to quasi-static loadings, high-rate loading can be regarded as an adiabatic deformation process. Normally, the strain hardening rate decreases due to adiabatic temperature rise softening which is from the irreversible plastic work in the samples. However, the strain hardening behavior for Mg-1.9Mn-0.3Ce alloy increases at high strain rates, which is totally different from other HCP metals such as $\alpha$ and $\alpha+\beta$ titanium alloys [27].
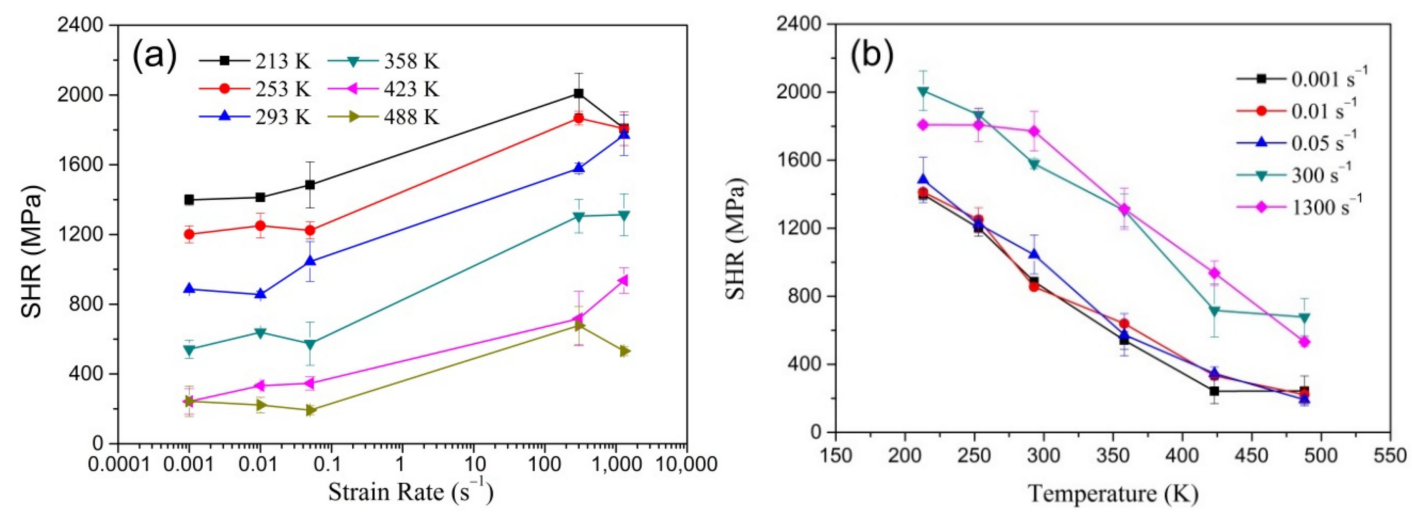

Figure 6. Effects of (a) strain rate and (b) temperature on the average values of strain-hardening rate.

\subsection{Deformation Mechanism and Fracture Behavior}

It should be emphasized that the fractured samples under high-rate loadings were used for EBSD analysis in the present investigation, implying that EBSD samples are not stretched to the identical strain levels in the high-rate tests. Due to the reflection of stress-pulse propagation in the incident and transmitted bars, a second loading is applied to the adhesively bonded tensile sample if the sample is not stretched to fracture after the first incident stress pulse passes through it, which results in a second plastic deformation in the sample. Consequently, it is quite difficult to carry out a high-rate loading-unloading procedure to acquire the sample deformed to a given strain level in the SHTB test. On the other hand, the fracture strains at high strain rates and various temperatures do not change too much, as shown in Figure 4e, suggesting that it is acceptable to compare and evaluate the EBSD results using high-rate fractured samples.

Figure 7 displays the $\{0001\}$ and $\{10 \overline{1} 0\}$ pole figures of deformed samples. It is clear that the sample after the tensile loading has a strong basal texture. The $\{0001\}$ basal plane is still parallel to the sheet surface, which is the result of basal dislocation activity. Furthermore, the movement of the central basal pole along the direction perpendicular to the loading axis shows that prismatic 
slip plays a prominent role in the plastic deformation, which was also observed in the tensile plastic deformation of $\mathrm{Mg}$-Al alloys subjected to quasi-static and dynamic loadings [18]. The emerging texture component is labeled with a black dotted circle in the $\{0001\}$ pole figures in Figure 7 , which is related to $\{10 \overline{1} 2\}$ tension twinning. The intensity of the emerging texture component is low, indicating that $\{10 \overline{1} 2\}$ tension twinning plays a weak role in tensile plastic deformation. Similarly, small amounts of $\{10 \overline{1} 2\}$ tension twinning were discovered in the AZ31 sheet after dynamic tensile in-plane loadings [18]. As seen in Figure 7, the pole figures under different loading conditions are similar, from which it can be extrapolated that the temperature and strain-rate have little effects on the tensile plastic deformation mechanism for $\mathrm{Mg}-1.9 \mathrm{Mn}-0.3 \mathrm{Ce}$ alloy sheet subjected to in-plane tensile loadings.

(a)
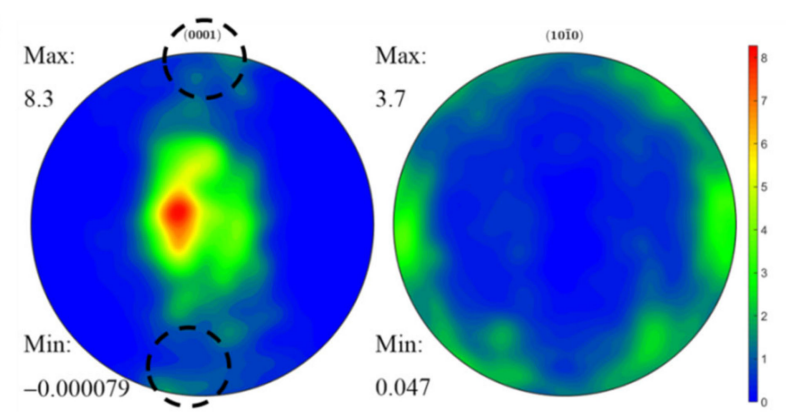

(b)
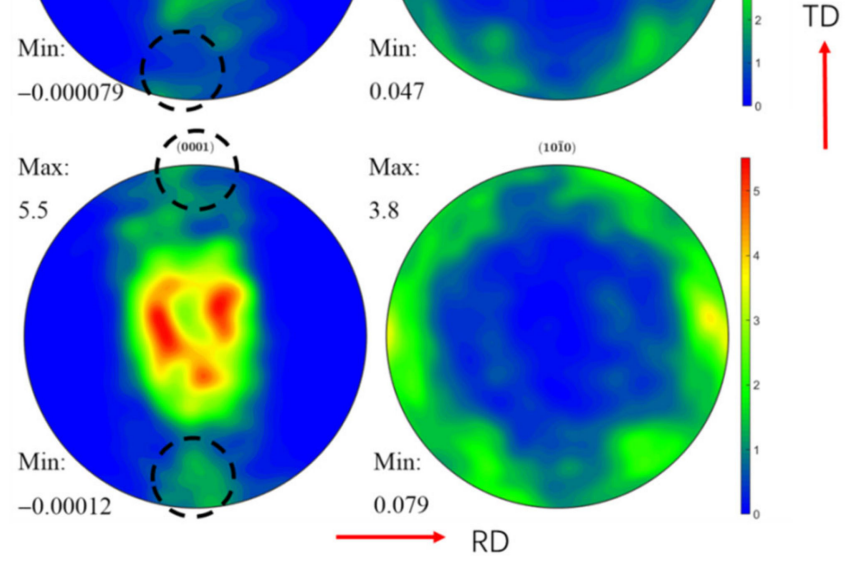

(c)

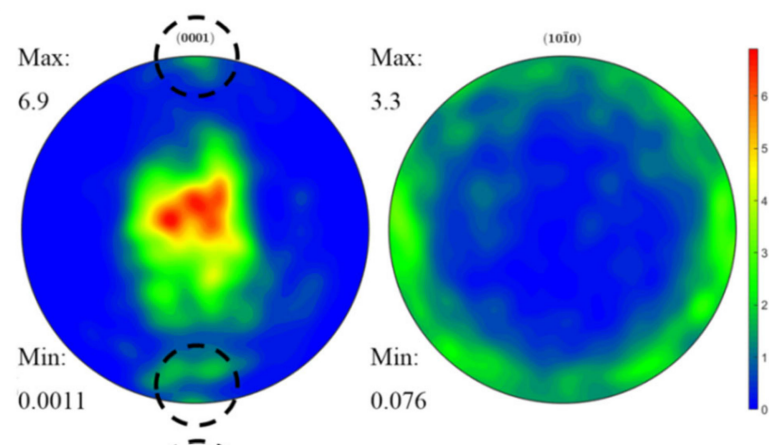

(d)

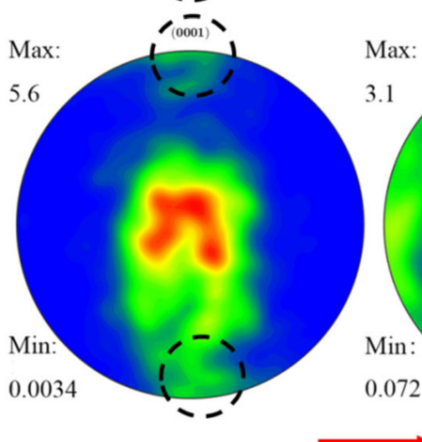

Max:

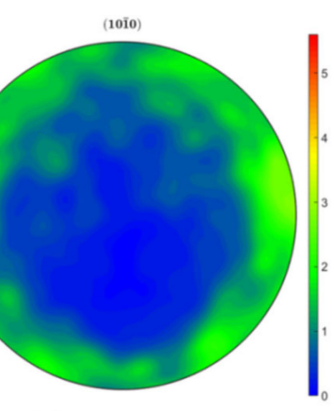

$\mathrm{RD}$

Figure 7. Pole figures of samples that loaded at (a) $0.001 \mathrm{~s}^{-1}$ and $293 \mathrm{~K}$, (b) $1300 \mathrm{~s}^{-1}$ and $293 \mathrm{~K}$, (c) $1300 \mathrm{~s}^{-1}$ and $213 \mathrm{~K}$, and (d) $1300 \mathrm{~s}^{-1}$ and $488 \mathrm{~K}$. 
Figure 8 presents the twin boundary maps in the deformed samples subjected to various strainrate and temperature loadings. Black lines indicate the grain boundary, and twin boundaries are marked by the lines of different colors, i.e., red lines indicate $\{10 \overline{1} 2\}$ tension twin, cyan lines indicate $\{10 \overline{1} 1\}$ compression twin, and yellow lines indicate $\{10 \overline{1} 1\}-\{10 \overline{1} 2\}$ double twin. Compared with the result for as-received alloy, obvious grain refinement is observed in the samples after tensile loadings. Grain refinement suggests the proliferation of high-angle grain boundaries, which is a characteristic of apparent non-basal slips. The $\{10 \overline{1} 2\}$ tension twinning, $\{10 \overline{1} 1\}$ compression twinning, and $\{10 \overline{1} 1\}-\{10 \overline{1} 2\}$ double twinning are also found, but the twins change little with strain rate and temperature.
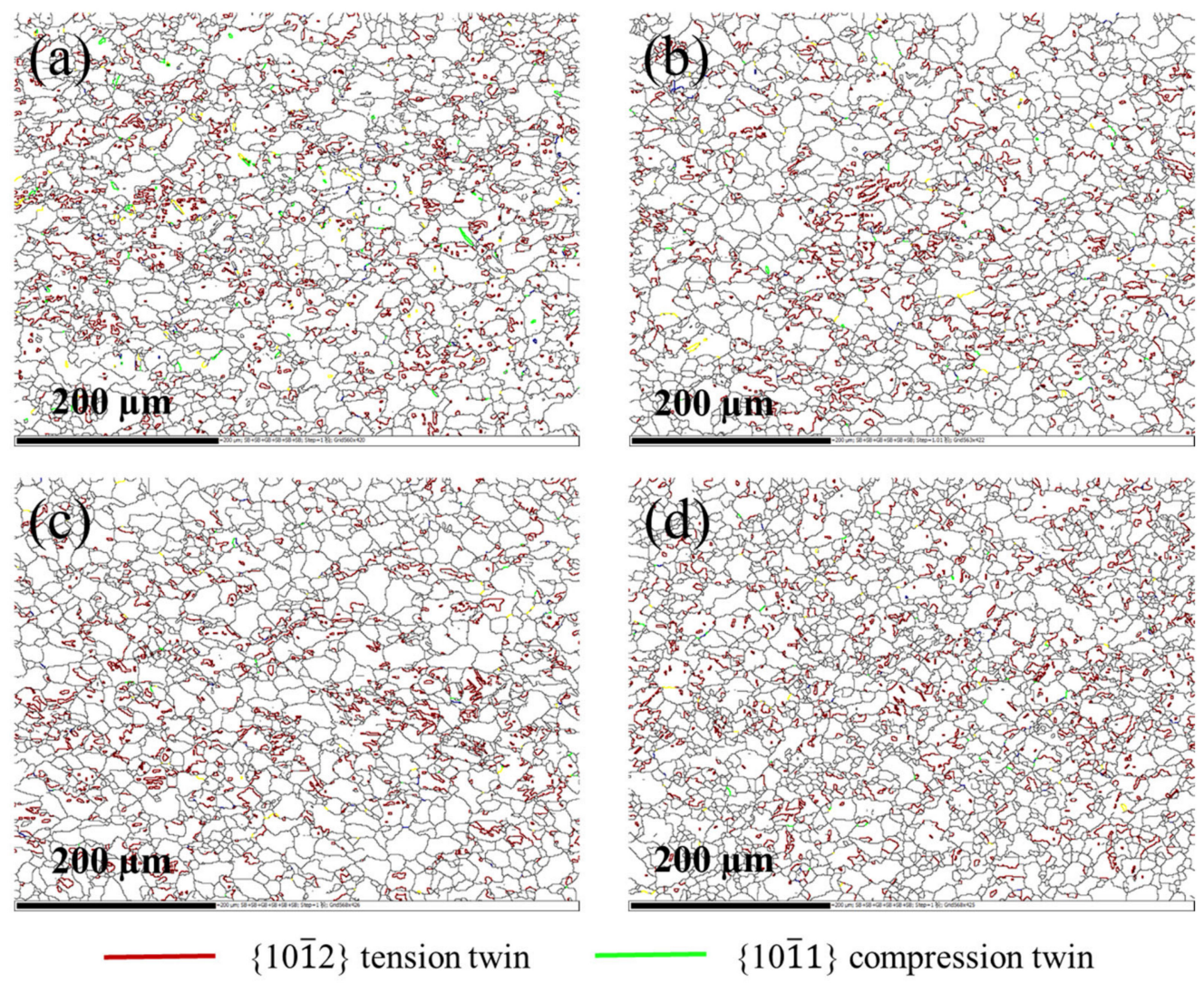

$\{10 \overline{1} 1\}-\{10 \overline{1} 2\}$ double twin

Figure 8. Twin boundary maps corresponding to the loading conditions of (a) $0.001 \mathrm{~s}^{-1}$ and $293 \mathrm{~K}$, (b) $1300 \mathrm{~s}^{-1}$ and $293 \mathrm{~K}$, (c) $1300 \mathrm{~s}^{-1}$ and $213 \mathrm{~K}$, and (d) $1300 \mathrm{~s}^{-1}$ and $488 \mathrm{~K}$.

Figure 9 shows the misorientation distribution in deformed samples. For clarity, the region with the misorientation angle greater than $10^{\circ}$ in the figure is enlarged locally. Some specific misorientation angles can be observed, for example, the $86^{\circ}$ misorientation angle corresponding to the $\{10 \overline{1} 2\}$ tension twin boundary. The misorientation distribution of high-angle grain boundaries in the as-received $\mathrm{Mg}-1.9 \mathrm{Mn}-0.3 \mathrm{Ce}$ alloy is approximately uniform. After tensile loadings, the grain boundaries with misorientation angle $86^{\circ}$ develop, which indicates $\{10 \overline{1} 2\}$ tension twinning takes part in the tensile plastic deformation. However, the fraction of twins is not high, and changes little under various tensile loading conditions, indicating that twinning is not the dominant mechanism in the tensile plastic deformation for $\mathrm{Mg}-1.9 \mathrm{Mn}-0.3 \mathrm{Ce}$ alloy sheet loaded in the rolling direction at both quasi-static and high rates. 

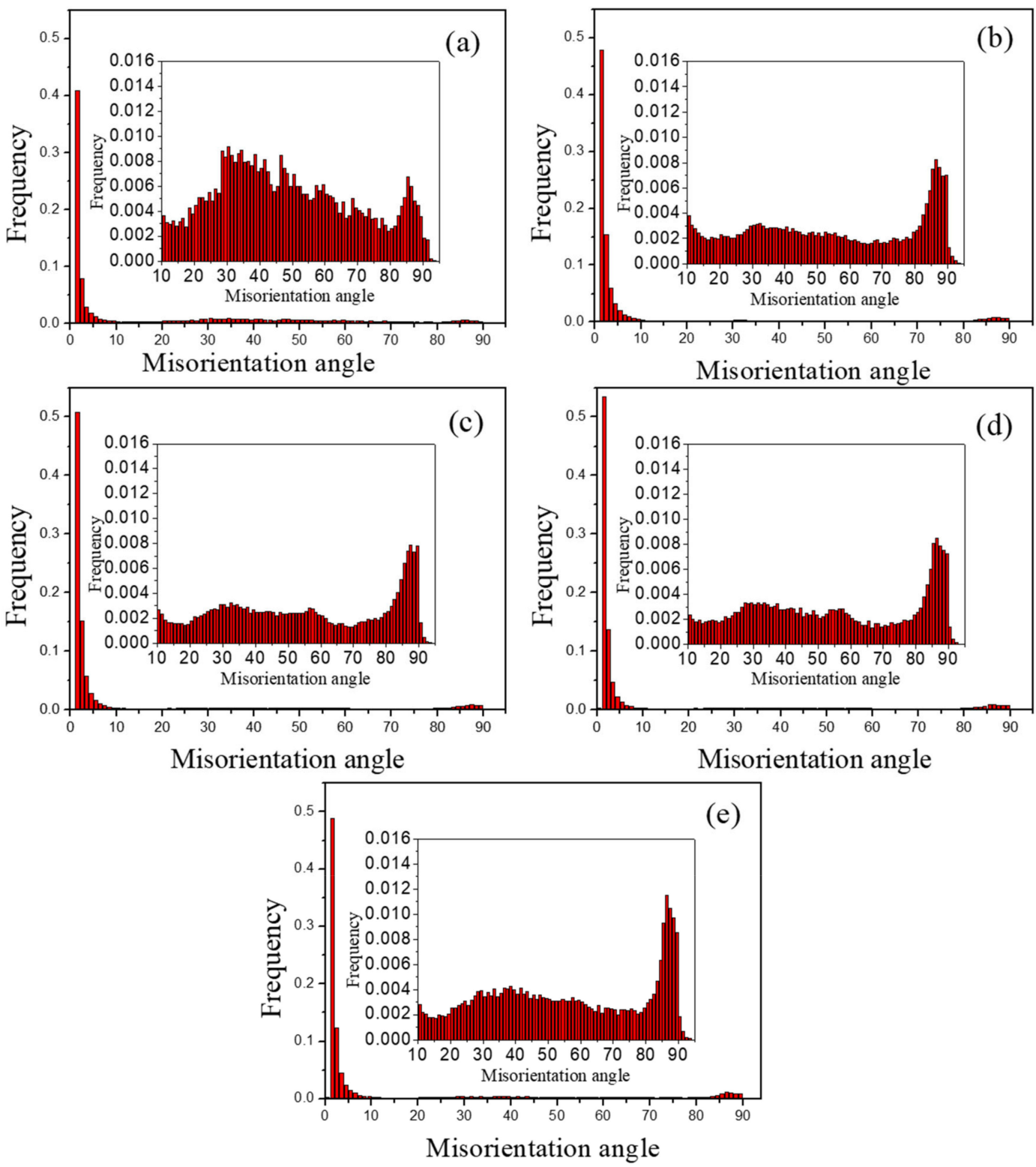

Figure 9. Misorientation distributions in samples obtained in (a) as-received Mg-1.9Mn-0.3Ce sheet, and samples loaded at (b) $0.001 \mathrm{~s}^{-1}$ and $293 \mathrm{~K}$, (c) $1300 \mathrm{~s}^{-1}$ and $293 \mathrm{~K}$, (d) $1300 \mathrm{~s}^{-1}$ and $213 \mathrm{~K}$, and (e) $1300 \mathrm{~s}^{-1}$ and $488 \mathrm{~K}$.

SEM (FEI Company, Eindhoven, The Netherlands) observations on fracture surfaces for tensile samples under different loading conditions are shown in Figure 10. River-like patterns and dimples occupy the fracture surfaces, which indicate that the fracture of Mg-1.9Mn-0.3Ce alloy exhibits a mixed mode of ductile and brittle fracture when the test temperature is equal to or below room temperature. When the strain rate is increased to the high- rate range, the number of dimples increases and the depth of dimples becomes deeper. When the ambient temperature rises to $423 \mathrm{~K}$, it is noticed in Figure 10e,f that the dimples are evenly distributed on the whole fracture surface, which is the obvious characteristic of ductile fracture. At ambient temperature of $423 \mathrm{~K}$, when the strain rate is increased to $1300 \mathrm{~s}^{-1}$, the diameter of the dimples on the fracture surface becomes smaller and the number of dimples increases. Khan et al. [19] carried out tensile tests on AZ31 alloy at various temperatures, and it was also found that the number of dimples in the fracture surface increased significantly with temperature. Precipitation can be found in Figure 10, and Mg-Mn-Ce and Mg-Ce precipitates can be identified with an average size of less than $0.5 \mu \mathrm{m}$, as illustrated in Figure 11. Mg-Mn-Ce precipitate is 
approximately spherical shaped, and Mn-Ce precipitate is in an irregular morphology. The number of $\mathrm{Mg}-\mathrm{Mn}$-Ce precipitates is greater than that of $\mathrm{Mg}$-Ce precipitates, while the volume fractions of these two phases are very small. At lower temperatures, brittle fracture occurs where river-like markings are found, which is related to the precipitates. However, as the test temperature increases, ductile fracture takes place.
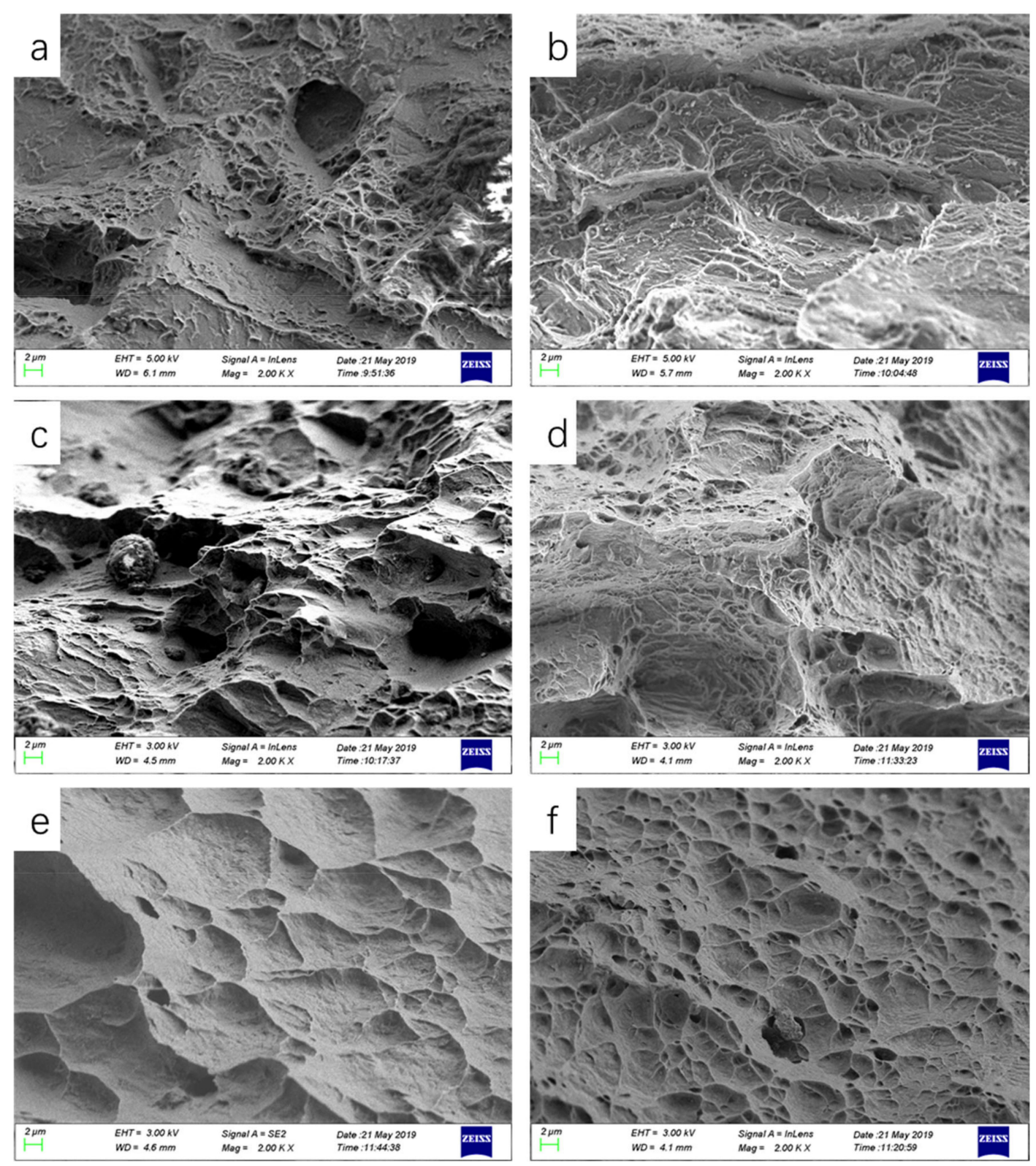

Figure 10. Morphologies of fracture surface for the samples stretched at (a) $0.001 \mathrm{~s}^{-1}$ and $213 \mathrm{~K}$, (b) $1300 \mathrm{~s}^{-1}$ and $213 \mathrm{~K}$, (c) $0.001 \mathrm{~s}^{-1}$ and $293 \mathrm{~K}$, (d) $1300 \mathrm{~s}^{-1}$ and $293 \mathrm{~K}$, (e) $0.001 \mathrm{~s}^{-1}$ and $423 \mathrm{~K}$, and (f) $1300 \mathrm{~s}^{-1}$ and $423 \mathrm{~K}$. 

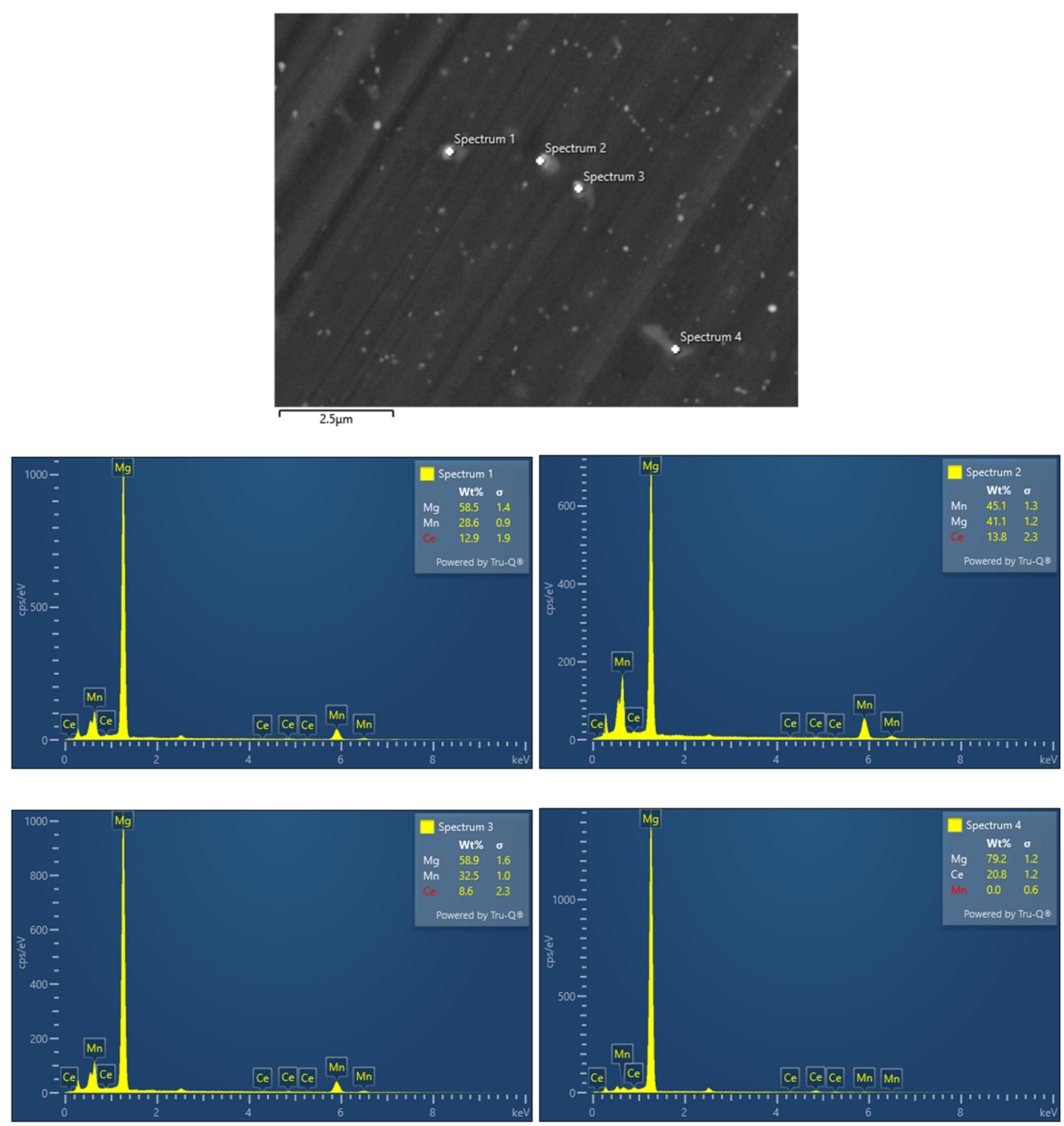

Figure 11. SEM examination of the precipitates in the Mg-1.9Mn-0.3Ce alloy.

\section{Conclusions}

Simple tensile experiments for rare-earth containing Mg-1.9Mn-0.3Ce alloy sheet along the rolling direction were performed within the strain rate and temperature ranges of $0.001-1300 \mathrm{~s}^{-1}$ and $213-488 \mathrm{~K}$. The tension stress-strain behavior, plastic deformation mechanism, and fracture mode of the alloy sheet are summarized as follows.

(1) Tensile behavior of $\mathrm{Mg}-1.9 \mathrm{Mn}-0.3 \mathrm{Ce}$ alloy sheet in the rolling direction has a positive strain-rate dependence and a negative temperature dependence. Both yield strength and strain hardening rate decrease with increasing test temperature, and increase with increasing strain rate. Especially, the strain-rate dependence for yield strength increases with temperature. Moreover, the strain hardening rate at high strain rates is much greater than for quasi-static ones.

(2) EBSD measurement indicates that basal slip and prismatic slip are the main plastic deformation mechanisms for Mg-1.9Mn-0.3Ce alloy sheet subjected to in-plane tensile loading. A small amount of $\{10 \overline{1} 2\}$ tension twinning occurs in the tensile plastic deformation, yet the fraction of twins changes little at high strain rates. 
(3) SEM observation shows that the mixture mode of ductile and brittle fracture changes into ductile type with increasing test temperature. Moreover, the diameter of the dimples decreases and the number of dimples increases under high-rate loadings at high temperatures.

Author Contributions: Conceptualization, Y.W.; methodology, J.W., Y.W., and Z.L.; formal analysis, J.W.; investigation, J.W. and Y.W.; writing-original draft preparation, J.W.; writing-review and editing, Y.W. and Z.L.; supervision, Y.W. and Z.L.; project administration, Y.W.; funding acquisition, Y.W. All authors have read and agreed to the published version of the manuscript.

Funding: This research was funded by the National Natural Science Foundation of China under grant number 11872359.

Conflicts of Interest: The authors declare no conflict of interest.

\section{References}

1. Yan, Y.; Deng, W.P.; Gao, Z.F.; Zhu, J.; Wang, Z.J.; Li, X.W. Coupled Influence of Temperature and Strain Rate on Tensile Deformation Characteristics of Hot-Extruded AZ31 Magnesium Alloy. Acta Met. Sin. Engl. Lett. 2016, 29, 163-172. [CrossRef]

2. Bae, S.W.; Kim, S.H.; Lee, J.U.; Jo, W.K.; Hong, W.H.; Kim, W.; Park, S.H. Improvement of mechanical properties and reduction of yield asymmetry of extruded Mg-Al-Zn alloy through Sn addition. J. Alloys Compd. 2018, 766, 748-758. [CrossRef]

3. Wei, J.; Wang, G.; Ji, X.; Deng, K.; Sha, F. Dynamic mechanical properties and constitutive relationship of particle-reinforced AZ91D composites. J. Alloys Compd. 2018, 767, 210-214. [CrossRef]

4. Singh, J.; Kim, M.S.; Lee, J.H.; Guim, H.; Choi, S. Microstructure evolution and deformation behaviors of E-form and AZ31 Mg alloys during ex-situ mini-V-bending tests. J. Alloys Compd. 2019, 778, 124-133. [CrossRef]

5. Monetta, T.; Parnian, P.; Acquesta, A. Recent Advances in the Control of the Degradation Rate of PEO Treated Magnesium and Its Alloys for Biomedical Applications. Metals 2020, 10, 907. [CrossRef]

6. Bohlen, J.; Nürnberg, M.R.; Senn, J.W.; Letzig, D.; Agnew, S.R. The texture and anisotropy of magnesium-zinc-rare earth alloy sheets. Acta Mater. 2007, 55, 2101-2112. [CrossRef]

7. Stanford, N.E.; Atwell, D.; Beer, A.; Davies, C.; Barnett, M. Effect of microalloying with rare-earth elements on the texture of extruded magnesium-based alloys. Scr. Mater. 2008, 59, 772-775. [CrossRef]

8. Li, X.; Al-Samman, T.; Gottstein, G. Mechanical properties and anisotropy of ME20 magnesium sheet produced by unidirectional and cross rolling. Mater. Des. 2011, 32, 4385-4393. [CrossRef]

9. Kamrini, S.; Fleck, C. Effects of calcium and rare-earth elements on the microstructureand tension-compression yield asymmetry of ZEK100 alloy. Mater. Sci. Eng. A 2014, 618, 238-243. [CrossRef]

10. Hidalgo-Manrique, P.; Robson, J.; Perez-Prado, M.T. Precipitation strengthening and reversed yield stress asymmetry in Mg alloys containing rare-earth elements: A quantitative study. Acta Mater. 2017, 124, 456-467. [CrossRef]

11. Lu, J.W.; Yin, D.; Huang, G.; Quan, G.; Zeng, Y.; Zhou, H.; Wang, Q. Plastic anisotropy and deformation behavior of extruded Mg-Y sheets at elevated temperatures. Mater. Sci. Eng. A 2017, 700, 598-608. [CrossRef]

12. Chai, Y.; He, C.; Jiang, B.; Fu, J.; Jiang, Z.; Yang, Q.; Sheng, H.; Huang, G.; Zhang, D.; Pan, F. Influence of minor Ce additions on the microstructure and mechanical properties of Mg-1.0Sn-0.6Ca alloy. J. Mater. Sci. Technol. 2020, 37, 26-37. [CrossRef]

13. Mirza, F.A.; Wang, K.; Bhole, S.; Friedman, J.; Chen, D.; Ni, D.; Xiao, B.; Ma, Z. Strain-controlled low cycle fatigue properties of a rare-earth containing ME20 magnesium alloy. Mater. Sci. Eng. A 2016, 661, 115-125. [CrossRef]

14. Geng, C.; Wu, B.; Du, X.; Wang, Y.; Zhang, Y.; Wagner, F; Esling, C. Stress-strain response of textured AZ31B magnesium alloy under uniaxial tension at the different strain rates. Mater. Sci. Eng. A 2013, 559, 307-313. [CrossRef]

15. Kurukuri, S.; Worswick, M.J.; Tari, D.G.; Mishra, R.K.; Carter, J.T. Rate sensitivity and tension-compression asymmetry in AZ31B magnesium alloy sheet. Philos. Trans. R. Soc. A Math. Phys. Eng. Sci. 2014, 372, 20130216. [CrossRef] 
16. Wang, W.; Chen, W.; Zhang, W.; Cui, G.; Wang, E. Weakened anisotropy of mechanical properties in rolled ZK60 magnesium alloy sheets with elevated deformation temperature. J. Mater. Sci. Technol. 2018, 34, 2042-2050. [CrossRef]

17. Habib, S.A.; Khan, A.S.; Gnäupel-Herold, T.; Lloyd, J.T.; Schoenfeld, S.E. Anisotropy, tension-compression asymmetry and texture evolution of a rare-earth-containing magnesium alloy sheet, ZEK100, at different strain rates and temperatures: Experiments and modeling. Int. J. Plast. 2017, 95, 163-190. [CrossRef]

18. Ulacia, I.; Dudamell, N.; Gálvez, F.; Yi, S.; Pérez-Prado, M.; Hurtado, I. Mechanical behavior and microstructural evolution of a Mg AZ31 sheet at dynamic strain rates. Acta Mater. 2010, 58, 2988-2998. [CrossRef]

19. Khan, A.S.; Pandey, A.; Gnäupel-Herold, T.; Mishra, R.K. Mechanical response and texture evolution of AZ31 alloy at large strains for different strain rates and temperatures. Int. J. Plast. 2011, 27, 688-706. [CrossRef]

20. Wang, X.; Mao, P.; Wang, R.; Liu, Z.; Wang, Z.; Wang, F.; Zhou, L.; Wei, Z. Role of $\{1012\}$ twinning in the anisotropy and asymmetry of AZ31 magnesium alloy under high strain rate deformation. Mater. Sci. Eng. A 2020, 772, 138814. [CrossRef]

21. Zhang, H.; Liu, Y.; Fan, J.; Roven, H.J.; Cheng, W.; Xu, B.; Dong, H. Microstructure evolution and mechanical properties of twinned AZ31 alloy plates at lower elevated temperature. J. Alloys Compd. 2014, 615, 687-692. [CrossRef]

22. Meyers, M.A.; Gray, G.T.; Thadhani, N.N. The dynamic behavior of materials: An introduction. JOM 2010, 62, 14-15. [CrossRef]

23. Siegkas, P.; Tagarielli, V.; Cui, H.; Lefebvre, L.P. Rate Dependence of the Compressive Response of Ti Foams. Metals 2012, 2, 229-237. [CrossRef]

24. Bhujangrao, T.; Froustey, C.; Iriondo, E.; Veiga, F.; Darnis, P.; Mata, F.A.G. Review of Intermediate Strain Rate Testing Devices. Metals 2020, 10, 894. [CrossRef]

25. Mitchell, D.; Xia, Y.; Wang, Y. Dynamic Testing of Materials with the Rotating Disk Indirect Bar-Bar Tensile Impact Apparatus. J. Test. Eval. 2007, 35, 100130-100135. [CrossRef]

26. Standardization Administration of the People's Republic of China. GB/T 228.1-2010. In Metallic Materials-Tensile Testing-Part 1: Method of Test at Room Temperature; Standardization Administration of the People's Republic of China: Beijing, China, 2011.

27. Zhang, J.; Wang, Y. Effect of strain rate on the tension behavior of Ti-6.6Al-3.3Mo-1.8Zr-0.29Si alloy at low temperatures. Mater. Sci. Eng. A 2014, 605, 59-64. [CrossRef]

Publisher's Note: MDPI stays neutral with regard to jurisdictional claims in published maps and institutional affiliations.

(C) 2020 by the authors. Licensee MDPI, Basel, Switzerland. This article is an open access article distributed under the terms and conditions of the Creative Commons Attribution (CC BY) license (http://creativecommons.org/licenses/by/4.0/). 